\title{
Corrigendum to "Origin of Boron and Brine Evolution in Saline Springs in the Nangqen Basin, Southern Tibetan Plateau"
}

\author{
Ji-long Han $\mathbb{D}^{1,2,3}$ Feng-qing Han $\mathbb{D}^{1,}{ }^{1,2}$ Syed-Asim Hussain, ${ }^{2,3}$ Wen-yu Liu, ${ }^{3}$ Xiu-qing Nian, ${ }^{3}$ \\ and Qing-fei $\mathrm{Mao}^{3}$ \\ ${ }^{1}$ Key Laboratory of Comprehensive and Highly Efficient Utilization of Salt Lake Resources, Qinghai Institute of Salt Lakes, \\ Chinese Academy of Sciences, Xining, Qinghai 810008, China \\ ${ }^{2}$ Qinghai Provincial Key Laboratory of Geology and Environment of Salt Lakes, Qinghai Institute of Salt Lakes, \\ Chinese Academy of Sciences, Qinghai Province, Xining 810008, China \\ ${ }^{3}$ University of Chinese Academy of Sciences, Beijing 100049, China
}

Correspondence should be addressed to Feng-qing Han; hfq15152@sina.com

Received 18 April 2018; Accepted 26 April 2018; Published 18 July 2018

Copyright (c) 2018 Ji-long Han et al. This is an open access article distributed under the Creative Commons Attribution License, which permits unrestricted use, distribution, and reproduction in any medium, provided the original work is properly cited.

In the article titled "Origin of Boron and Brine Evolution in Saline Springs in the Nangqen Basin, Southern Tibetan Plateau" [1], there was an error in the order of the second and third affiliations. Additionally, the Laboratory name in the second affiliation should be changed from "Key Laboratory of Salt Lake Geology and Environment of Qinghai Province" to "Qinghai Provincial Key Laboratory of Geology and Environment of Salt Lakes." The corrected affiliation list is shown above.

\section{References}

[1] J.-1. Han, F.-q. Han, S.-A. Hussain, W.-y. Liu, X.-q. Nian, and Q.-f. Mao, "Origin of boron and brine evolution in saline springs in the Nangqen Basin, southern Tibetan Plateau," Geofluids, vol. 2018, Article ID 1985784, 12 pages, 2018. 

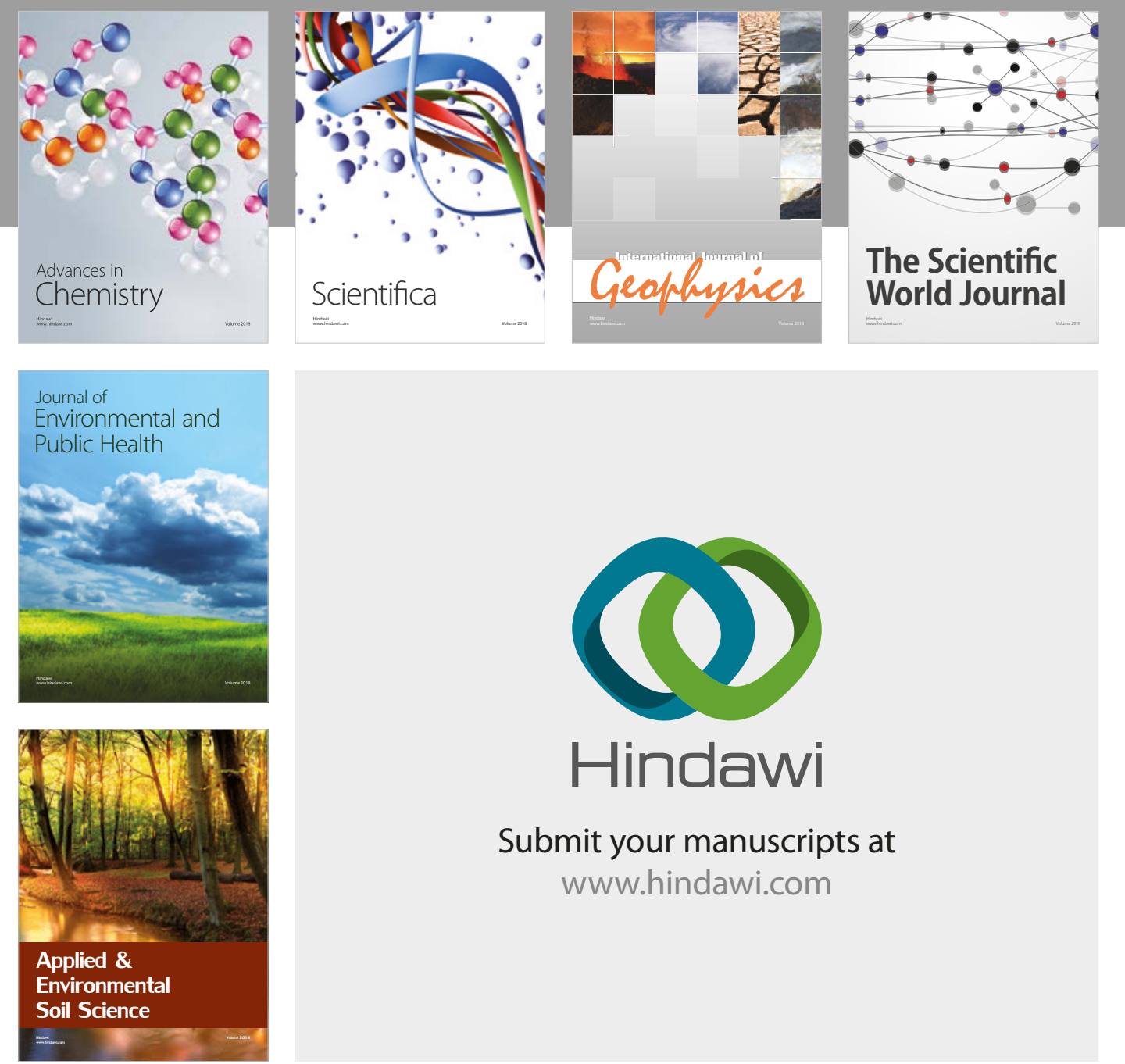

The Scientific

\section{World Journal}
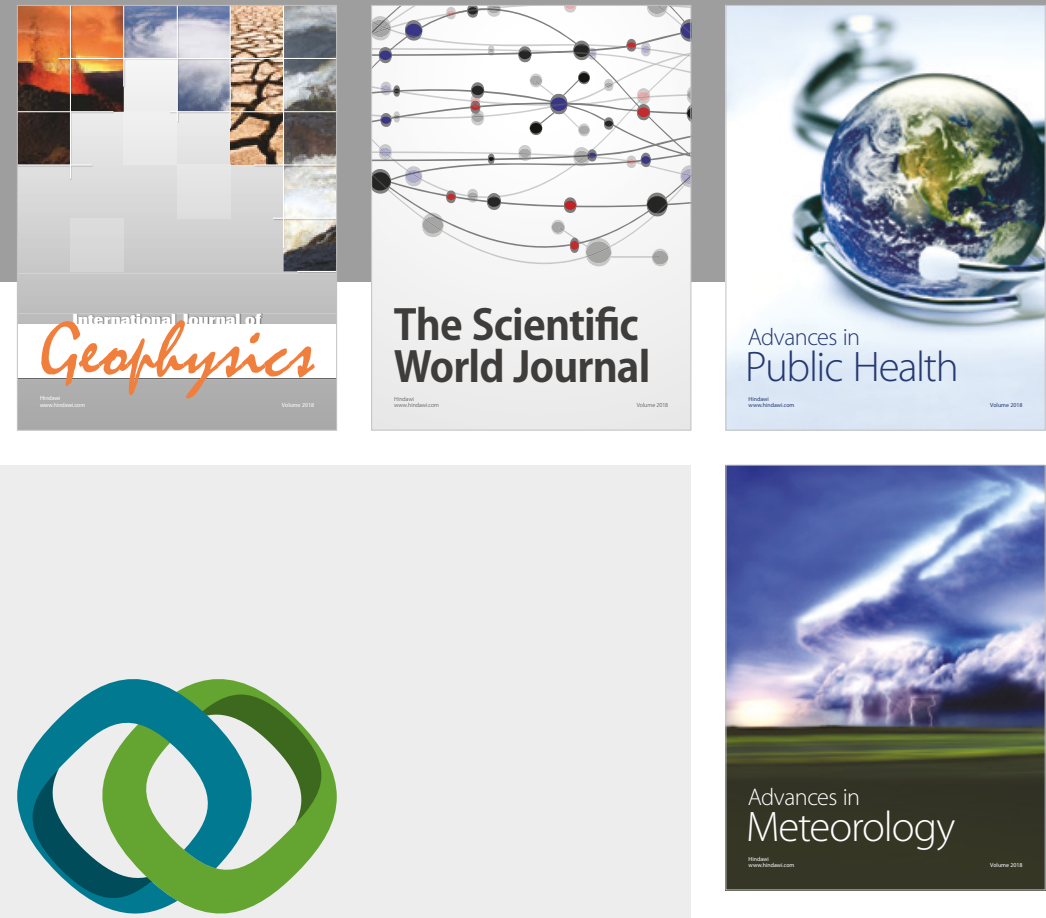

Advan

Public Health

\section{Hindawi}

Submit your manuscripts at

www.hindawi.com
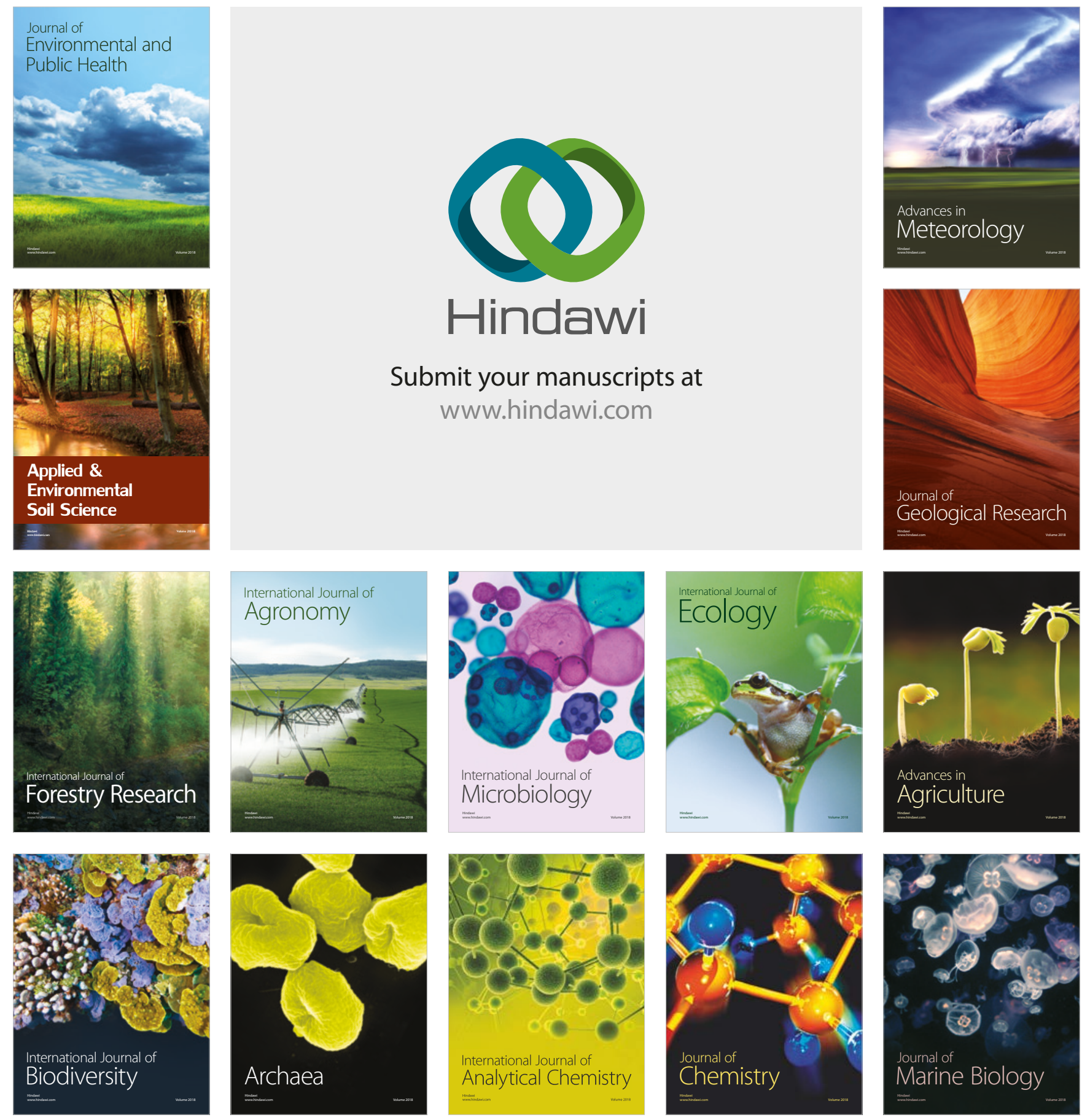